remained more or less stable for a time but later deteriorated seriously. In three either the dose of diuretics had been increased or a second diuretic had been added. A second important factor in three patients was the addition of a non-steroidal anti-inflammatory drug. Inhibition of the formation of renal prostaglandin by non-steroidal antiinflammatory drugs may cause rapid deterioration of renal function. ${ }^{13-15}$

Among the 142 patients with raised concentrations of creatinine or urea, $28(20 \%)$ had previously received captopril. Of the 771 patients without evidence of renal impairment, $84(11 \%)$ had received captopril. It was not possible to judge whether captopril had already caused some degree of renal impairment in these patients before they began enalapril.

This exhaustive investigation failed to find any patient with mild or moderate uncomplicated hypertension who died of renal failure as a result of taking enalapril. On the other hand, we encountered several important factors which might have been avoided. No unexpected effects of enalapril were found.

We thank the family practitioner committees and the hospitals for case notes, the Office of Population Censuses and Surveys for the death entries, and the general practitioners and consultants who made this study possible. We also thank colleagues who processed the case notes and Mrs Georgina
Spragg for preparing the manuscript. The work was funded in part by a grant from Merck Sharp and Dohme.

1 Committee on Safety of Medicines. Current problems. No 17. London: HMSO, 1986

2 Hollenberg NK. Renal response to angiotensin-converting enzyme inhibition. Am F Cardiol 1983;49:1425-9.

3 Blythe WB. Captopril and renal autoregulation. $N$ Engl F Med 1983;308: 390-1.

4 Schreiber MJ Jr, Fang LST. Renal failure associated with captopril. fAMA 1983;250:31.

5 Inman WHW, Rawson NSB, Wilton LV, Pearce GL, Speirs CJ. Post-marketing surveillance of enalapril. I: Results of prescription-event monitoring. Br Med F 1988;297:826-9.

6 Consensus Trial Study Group. Effects of enalapril on mortality in severe congestive heart failure. N Engl f Med 1987;316:1429-35.

7 Cooper WD, Sheldon D, Brown D, Kimber GR, Isitt VL, Currie WJC. Postmarketing surveillance of enalapril: experience in 11,710 hypertensive patients in general practice. $\mathcal{I} R$ Coll Gen Pract 1987;37:346-9.

8 Wilson JR, Schwartz JS, Sutton MS-J, et al. Prognosis in severe heart failure: relation to hemodynamic measurements and ventricular ectopic activity. f Am Coll Cardiol 1983;2:403-10.

9 Veterans Administration Cooperative Study Group on Antihypertensive Agents. Low dose captopril for the treatment of mild to moderate hypertension. Arch Intern Med 1984;144:1947-53.

$10 \mathrm{Knauf} \mathrm{H}$, Reuter $\mathrm{K}$, Mutschler $\mathrm{E}$. Limitation on the use of amiloride in early renal failure. Eur f Clin Pharmacol 1985;28:61-6.

11 Knauf H, Mohrke W, Mutschler E. Delayed elimination of triamterene and its active metabolite in renal failure. Eur f Clin Pharmacol 1983;24:453-6.

12 Neale TJ, Lynn KL, Bailey RR. Spironolactone-associated aggravation of renal functional impairment. $N Z$ Med $\mathcal{F}$ 1976;83:147-9.

13 Clive DM, Stoff DS. Renal syndromes associated with non-steroidal anti-inflammatory drugs. $N$ Engl $F$ Med 1983;308:373-6.

14 Cinotti GA, Manzi M, Mene P, et al. Prostaglandin dependence of renal function in chronic glomerular disease. Clin Res 1982;30:445A

15 Favre L, Glasson P, Vallotton MB. Reversible acute renal failure from combined triamterene and indomethacin. A study in healthy subjects. Ann Intern Med 1982;96:317.

(Accepted 10 fune 1988)

\title{
Fertility and legal abortion in England and Wales: performance indicators for family planning services
}

\author{
Michael Clarke
}

\begin{abstract}
The relation between fertility rates and legal abortion rates was investigated in a sample of health authorities in England and Wales to see how these varied. Total period fertility rates and total period legal abortion rates were derived from the average number of live births or legal abortions that would be experienced per woman if women experienced the age specific rates of the year in question throughout their childbearing years. The sample of 30 health authorities was selected by taking the districts with the highest and lowest fertility rates in each English region and in Wales in 1986. Total period fertility rates varied from 1.37 in Riverside to 2.42 in Tower Hamlets, while abortion rates varied from 0.25 in East Yorkshire to $\mathbf{0 . 9 9}$ in Riverside. When the two rates were added to provide a potential fertility rate it became clear that some districts with similar potential fertility rates had very different underlying component rates.

Such comparisons can be used for service monitoring, indicating the need for better abortion and family planning services in districts with high fertility rates and for better family planning services in those with high abortion rates.
\end{abstract}

\section{Introduction}

In 1971 there were 95000 legal abortions undertaken on women living in England and Wales and 783000 live births, a ratio of one abortion to just over eight live births. By 1986 there were 148000 legal abortions ${ }^{1}$ and 661000 live births, ${ }^{2}$ a ratio of one abortion to just over four live births. This paper describes the relation between fertility rates and legal abortion rates in
England and Wales and shows how these measures vary within a sample of health authorities.

The sample of health authorities was chosen by taking from each regional health authority in England and Wales the districts with the highest and the lowest fertility rates in 1986. Thus 30 district health authorities were sampled, which covered the total range of fertility in England and Wales in 1986 but not necessarily the total range of abortion rates.

\section{Methods}

As abortions and live births tend to occur to women at different ages one of the ways to compare fertility and abortions is by using total period fertility rates and total period legal abortion rates. These measures estimate the average number of live births or legal abortions which would be experienced per woman if women experienced the age specific fertility or abortion rates of the calendar year in question throughout their childbearing life span. The rates were derived by summing the fertility or legal abortion rate for a given year by single years of age, or age bands, across the fertile age range. These cumulative lifetime rates represent a variety of direct age standardised incidence rates without the arbitrariness of choosing a standard population. ${ }^{3}$ Both the data sets use the usual place of residence, rather than place of delivery or place of operation, which is preferable to information on place of medical care.

\section{Results}

A hypothetical average woman in England and Wales experiencing the present fertility rates through 

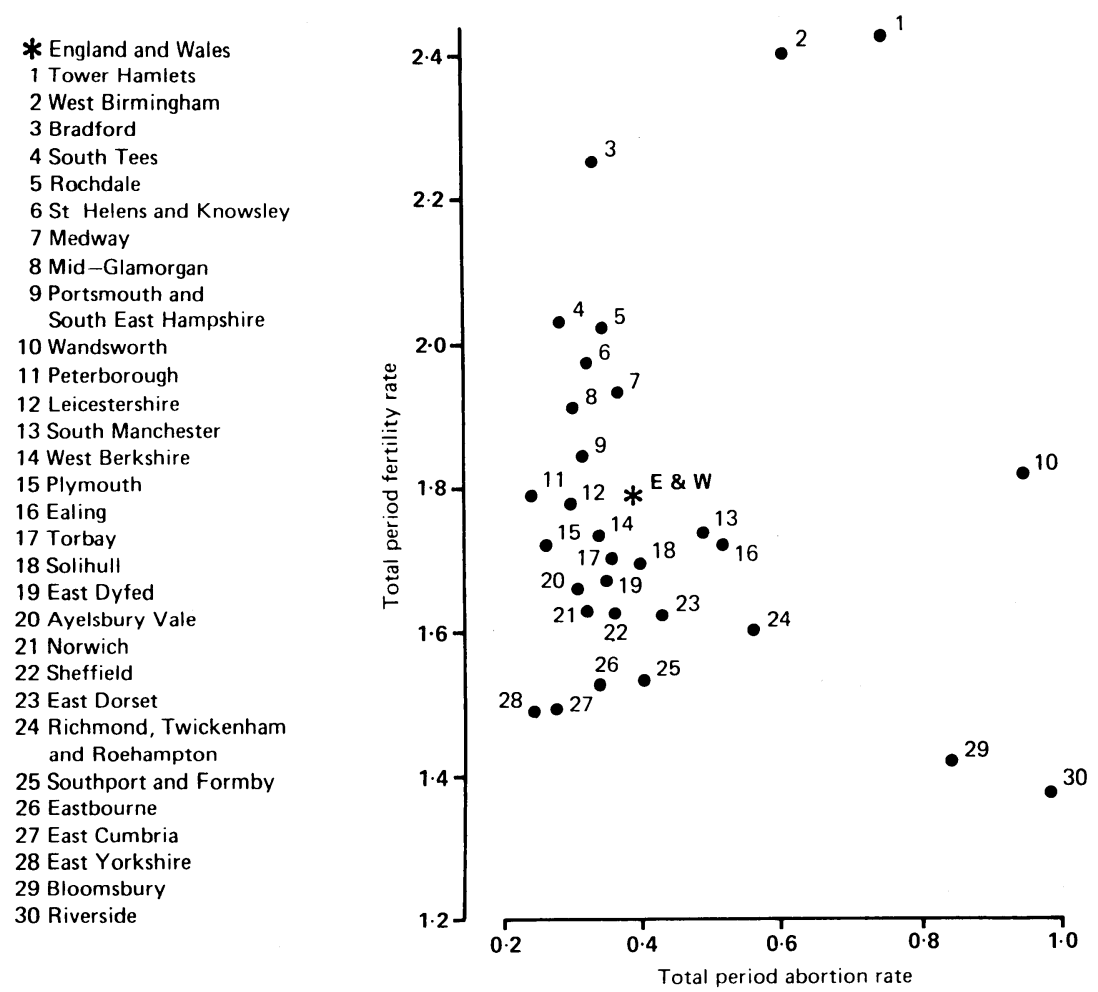

Relation between total period fertility and total period abortion rates in selected health districts in England and Wales 1986

her lifetime would expect to have 1.8 children. Similarly, on average, more than one woman in three might have a legal abortion.

The figure illustrates how the total period fertility and abortion rates varied among the sample of health districts. Fertility varied by almost twofold, from $2 \cdot 42$ in Tower Hamlets to 1.37 in Riverside. Legal abortion rates varied by nearly fourfold, from 0.99 in Riverside to 0.25 in East Yorkshire.

With the exception of two health authorities (Tower Hamlets and West Birmingham) the seven health authorities with total period fertility rates higher than the national average had total period abortion rates lower than the average. When the rates were summed to make a very crude potential fertility rate it was interesting to note that health districts with similar potential fertility rates produced the components of these rates very differently. For example, South Tees and Bloomsbury had potential fertility rates of around $2 \cdot 3$, but as a result of their different abortion rates their respective total period fertility rates were $2 \cdot 0$ and $1 \cdot 4$, almost at the opposite extremes of the national fertility distribution. Two health authorities, Bloomsbury and Riverside, reduced their potential fertility rates from above the national average to the two lowest fertility rates in the sample by a high legal abortion rate.

\section{Discussion}

Health authorities and family practitioner committees should be encouraged to use total period fertility and abortion rates for service monitoring. Authorities with high fertility rates should review both abortion and family planning provision, while those with high abortion rates should review their family planning programmes.

The data to calculate these summaries of fertility and abortion are already made available by the Office of Population Censuses and Surveys to health authorities and as such provide an opportunity to create valuable demographic, outcome based performance indicators for primary care, family planning, and hospital abortion services.

I thank the Office of Population Censuses and Surveys for providing the district health authority data, Elizabeth Draper for statistical help, and Bill Brass, David Clayton, and Paul Burton for their helpful comments.

1 Office of Population Censuses and Surveys. Abortion statistics 1986. London: HMSO, 1987. (AB No 13.)

2 Office of Population Censuses and Surveys. Birth statistics 1986. London: HMSO, 1988. (FMI No 15.)

3 Day NE. Cumulative rate and cumulative risk. In: Waterhouse J, Muir C, Shanmugaratnam K, Powell J, eds. Cancer incidence in five countries. Vol IV. Lyon: International Agency for Research on Cancer, 1982.

(Accepted 5 August 1988)
Departments of Geriatric

Medicine and

Gastroenterology,

Northern General

Hospital, Sheffield

Michael P Skander, MRCP, senior registrar

Francis P Ryan, FRCP,

consultant physician

Correspondence to:

Dr Ryan.

\section{Non-steroidal anti-inflammatory drugs and pain free peptic ulceration in the elderly}

\author{
Michael P Skander, Francis P Ryan
}

Non-steroidal anti-inflammatory drugs can damage the gastric and duodenal mucosa. ${ }^{2}$ The elderly, particularly women, are at greater risk of such damage. ${ }^{23}$ We were concerned that in addition to having ulcerogenic properties these drugs might modify the symptoms of peptic ulcers in older people.

Presenting complaint of patients aged 65 and over with gastric or duodenal ulcers at endoscopy, and ingestion of non-steroidal anti-inflammatory drugs (NSAIDs) in preceding six weeks

\begin{tabular}{lcccccc}
\hline & \multicolumn{2}{c}{ Patients aged 65-74 } & & \multicolumn{2}{c}{ Patients aged $\geqslant 75$} \\
\cline { 2 - 3 } \cline { 5 - 6 } $\begin{array}{c}\text { Presenting } \\
\text { complaint }\end{array}$ & Had taken NSAIDs & Had not taken NSAIDs & & Had taken NSAIDs & Had not taken NSAIDs \\
\hline Dyspepsia & 12 & 14 & & $6^{\star}$ & 13 \\
No dyspepsia & 11 & 2 & & 14 & 7 \\
Bleeding & 5 & 2 & 12 & 3 \\
Anaemia & 2 & 1 & 4 & 1 \\
Other & 4 & & & & &
\end{tabular}

${ }^{\star} \mathrm{p}<0.001\left(\chi^{2}\right.$ test $)$
This would lead to a delay in diagnosis, which could contribute to the poorer prognosis of peptic ulcer disease in the elderly. ${ }^{4}$

\section{Patients, methods, and results}

This study was part of a detailed prospective analysis of all elderly patients who had an endoscopy at this hospital over one year. Patients were referred from general physicians (55\%), geriatricians (33\%), and surgeons and haematologists (12\%). All endoscopies were carried out by one of us (MPS) with an Olympus XQ10 after local anaesthesia and with the patient's informed consent. Before intubation we recorded the presenting symptoms on a form, and after endoscopy we took a detailed drug history with particular reference to any use of non-steroidal anti-inflammatory drugs in the preceding six weeks. For analysis we divided patients into two age groups: $65-74$ and 75 and over.

After patients with malignant ulcers and superficial erosions had been excluded 98 patients aged 65 and over were found to have either gastric or duodenal ulcers at endoscopy. Of these, 54 were women ( 34 aged $\geqslant 75)$ and 44 men $(21$ aged $\geqslant 75)$. Sixty patients had gastric ulcers ( 37 women) and 38 had duodenal ulcers (17 women).

Thirty six of the 56 patients aged $\geqslant 75$ had taken non-steroidal anti-inflammatory drugs during the six 